\title{
Valve-sparing root replacement for pulmonary autograft dissection late after the Ross operation
}

\author{
Giovanni Battista Luciani, MD, Alessandro Favaro, MD, Francesca Viscardi, MD, Paolo Bertolini, MD, and \\ Alessandro Mazzucco, MD, Verona, Italy
}

A

ortic valve replacement with the pulmonary autograft (ie, the Ross operation) is generally associated with satisfactory early and late results. Complications, however, can occur, including the tendency of the pulmonary autograft root to dilate with time. ${ }^{1}$ Whereas neoaortic root dilatation might be observed in as many as one third of patients late after the Ross operation, ${ }^{2}$ uncertainty still exists as to the rate of progression toward true aneurysmal disease (aortic diameter $\geq 5 \mathrm{~cm}) .{ }^{1,2}$ Furthermore, the actual risk of complications, such as neoaortic rupture or dissection, is also unknown. The yet undefined natural history of root dilatation after the Ross operation, the often satisfactory competence of the pulmonary autograft valve, the scarcity of valid therapeutic alternatives (particularly in the infant and child), and the complexity-risk of reintervention have thus far delayed standardization of therapeutic indications. In particular, timing and technique of reoperation on the aneurysmal neoaortic root are still controversial. ${ }^{1,2}$

Here we present a case of potentially lethal evolution of progressive pulmonary autograft dilatation (ie, neoaortic root dissection) successfully treated with valve-sparing root replacement. The implications in terms of natural history and indications for reintervention are discussed.

\section{Clinical Summary}

A 29-year-old man with a long-standing history of aortic valve regurgitation on the bicuspid aortic valve and mild dilatation of the aortic root underwent elective aortic root replacement with the pulmonary autograft on October 18, 1994. The right ventricular outflow tract was reconstructed with a $28-\mathrm{mm}$ pulmonary homograft. Postoperative recovery was uneventful, and discharge echocardiography showed competent semilunar valves and normal aortic root diameter. Two years after the operation, moderate dilatation of the aortic root (maximum diameter, $46 \mathrm{~mm}$ ) was identified at yearly echocardiographic examination. The aortic valve, however, was competent, and the patient was completely symptom free. Subsequent examinations confirmed progressive root dilatation, which reached true aneurysmal dimensions 8 years

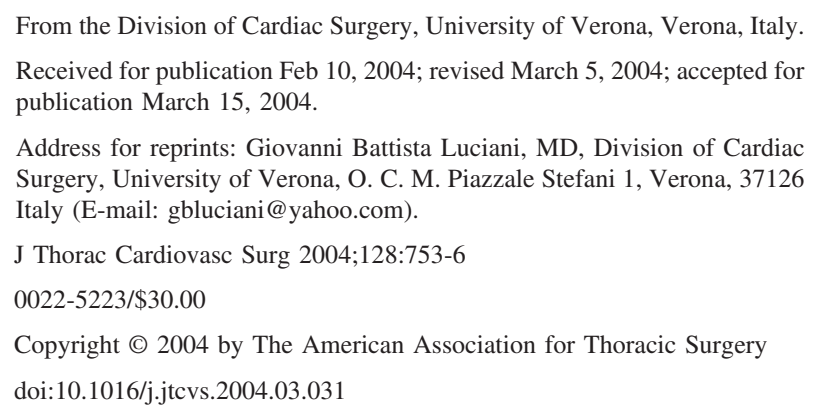

after the operation. The latest measurement showed a left ventricular aortic junction (aortic annulus) diameter of $32 \mathrm{~mm}$, a sinus of Valsalva diameter of $48 \mathrm{~mm}$, and a sinotubular junction and proximal ascending aortic diameter of $54 \mathrm{~mm}$. The aortic valve presented with mild regurgitation, and mild obstruction of the pulmonary homograft (peak pressure gradient of $24 \mathrm{~mm} \mathrm{Hg}$ ) was also identified. Although the patient remained asymptomatic, elective resection of the root aneurysm was recommended, and preoperative angiographic examination was scheduled. On admission for preoperative screening on July 16, 2003, the patient reported the recent onset of mild exertional dyspnea.

Repeat echocardiographic examination of the aortic root suggested a further increase in maximum root diameter $(63 \mathrm{~mm}$ at the sinus of Valsalva portion), with the presence of an intimal flap image. Aortic valve function had worsened to produce moderate insufficiency, and mild dilatation of the left ventricle (left ventricular end-diastolic dimension of $65 \mathrm{~mm}$ ) with normal systolic function (ejection fraction of 65\%) was also present. These findings were corroborated by means of aortic angiography, showing severe aortic root dilatation with straightening of the posterior profile of the root, which suggested the presence of an intimal flap (Figure 1). Valve insufficiency was graded as mild, and the results of coronary angiography were normal. Magnetic resonance scanning of the ascending aorta confirmed the diagnosis of aortic root aneurysm, with dissection limited to the root itself. The distal ascending aorta, the arch, and the descending thoracic aorta were unremarkable. Given the likelihood of acute or subacute neoaortic root dissection, the patient was transferred to our unit for urgent repair. On sternal re-entry, marked dilatation of the aortic root was identified. By using mildly hypothermic cardiopulmonary bypass, the distal ascending aorta was crossclamped, and the heart was arrested with retrograde blood cardioplegia. After transection of the aorta at the level of the distal aortic anastomosis, marked thinning of the aortic root wall was evident. An intimal flap extending from the level of the aortotomy to the noncoronary sinus of Valsalva was found. The left and right coronary sinuses were intact.

Because the pulmonary autograft valve appeared normal, aortic root remodeling with the Yacoub technique was performed with a size 30 Dacron graft. After weaning from cardiopulmonary bypass, intraoperative transesophageal echocardiography showed only trace aortic insufficiency. Postoperative recovery proved uneventful, with discharge on the seventh postoperative day without cardiac medication. Histologic examination of the pulmonary autograft wall demonstrated cystic medial necrosis, with fragmentation and loss of elastic fibers and moderate deposition of mucopolysaccharide material (Figure 2). On follow-up examination, the patient is in New York Heart Association class I and presents with mild autograft aortic valve insufficiency, with an aortic annulus diameter of $30 \mathrm{~mm}$, a sinus of Valsalva and sino- 

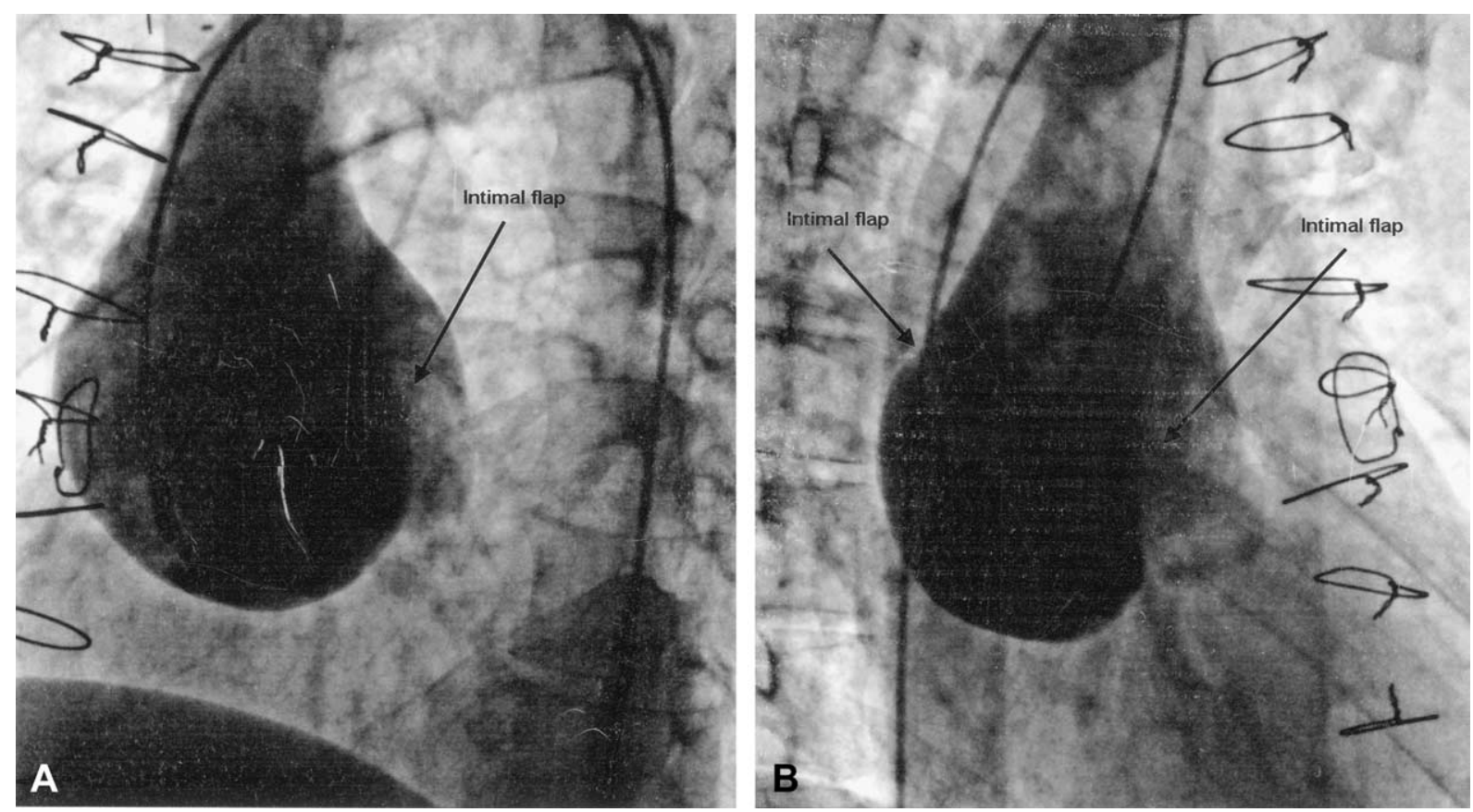

Figure 1. Left anterior oblique (A) and right anterior oblique (B) view of aortic root angiogram. Severe $(>6 \mathrm{~cm})$ root dilatation is apparent. An intimal flap limited to the aortic root can be suspected on the basis of the straightening of the posterior border of the aortic root.
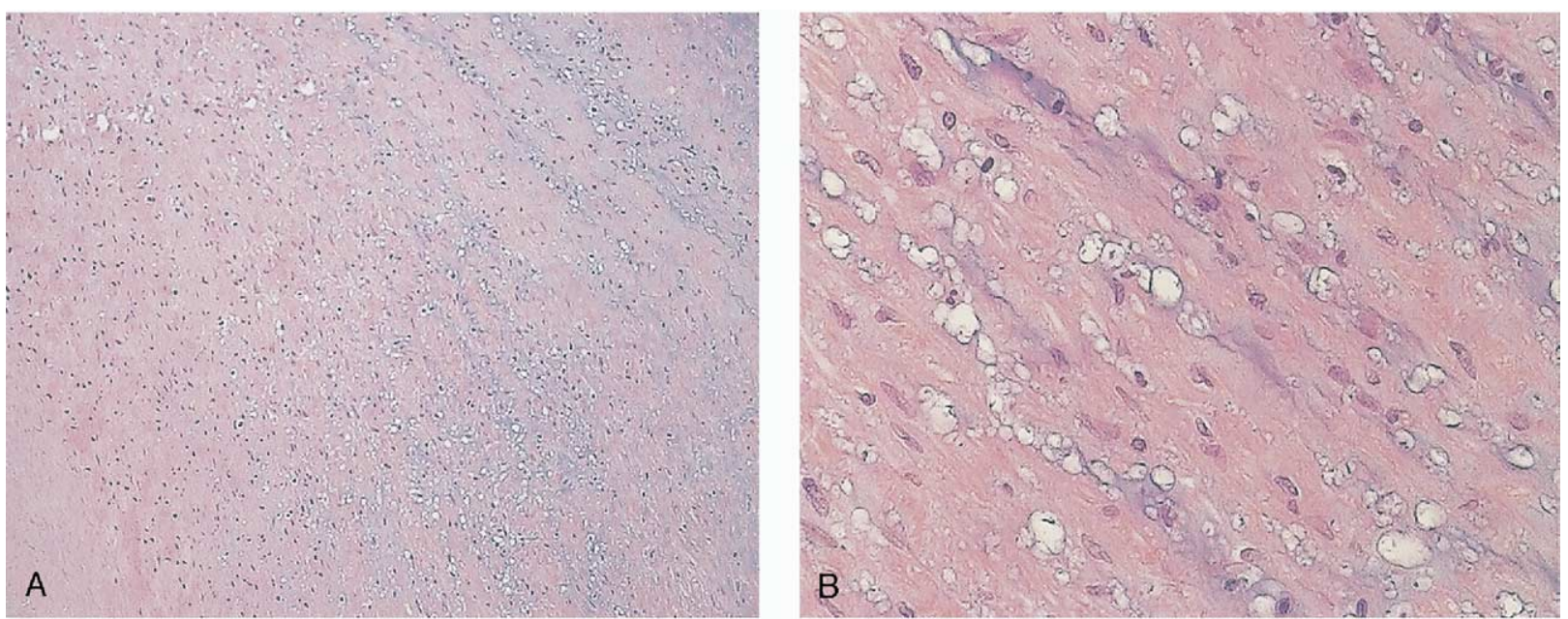

Figure 2. Histology of the resected pulmonary autograft root wall showing cystic medial necrosis with moderate deposition of mucopolysaccharide material (hematoxylin and eosin stain; A, original magnification 100×; B, original magnification $200 \times$ ).

tubular junction diameter of $36 \mathrm{~mm}$, and a proximal ascending aorta diameter of $34 \mathrm{~mm}$ on the latest echocardiographic assessment 6 months after reoperation.

\section{Discussion}

Despite widespread satisfaction with the clinical outcome of the Ross operation, awareness of its early and late shortcomings is growing. ${ }^{1,2}$ Neoaortic root dilatation has since emerged as the most common complication, particularly when the autograft is implanted with the complete root replacement technique. ${ }^{1,2}$ The proportion of patients with root dilatation who show progression toward true neoaortic aneurysm (aortic diameter $\geq 5 \mathrm{~cm}$ ) and the rate of progression are matters of controversy. ${ }^{1,2}$ Quite clearly, however, progressive autograft root dilatation has been shown to cause neoaortic valve insufficiency. ${ }^{2,3}$ This observation explains the increasing number of recent reports on elective reoperations for 
TABLE 1. Patients undergoing resection of aortic aneurysm after the Ross operation

\begin{tabular}{|c|c|c|c|c|c|c|c|}
\hline $\begin{array}{l}\text { Age (y), } \\
\operatorname{sex}(M / F)\end{array}$ & Original disease & Ross technique & $\begin{array}{l}\text { Interval } \\
\text { after Ross } \\
\text { operation } \\
\text { (y) }\end{array}$ & $\begin{array}{c}\text { Maximum aortic } \\
\text { diameter }(\mathrm{mm})\end{array}$ & $\begin{array}{l}\text { Valve function } \\
\text { at reoperation }\end{array}$ & $\begin{array}{l}\text { Technique of } \\
\text { reoperation }\end{array}$ & $\begin{array}{c}\text { Pulmonary } \\
\text { autograft } \\
\text { histology }\end{array}$ \\
\hline $31, \mathrm{M}$ & AS, Al, bicuspid & $\begin{array}{l}\text { Root replacement, } \\
\text { sinus obliteration } \\
\text { technique }\end{array}$ & 7 & 62 , sinus portion & Severe Al & $\begin{array}{l}\text { Composite root } \\
\text { replacement } \\
\text { (Hancock II 23 } \\
\text { + Vascutek 26) }\end{array}$ & CMN \\
\hline $38, \mathrm{M}$ & Al, tricuspid & $\begin{array}{l}\text { Root replacement, } \\
\text { inflow-outflow } \\
\text { pericardial } \\
\text { support }\end{array}$ & 6 & 47, STJ & Severe Al & $\begin{array}{l}\text { Composite root } \\
\text { replacement } \\
\text { (Cryolife- } \\
\text { O'Brien } 25+ \\
\text { Vascutek 26) }\end{array}$ & CMN \\
\hline $38, \mathrm{M}$ & Al, bicuspid & Root replacement & 9 & 63 , sinus portion & Moderate Al & $\begin{array}{l}\text { Yacoub root } \\
\text { remodeling }\end{array}$ & CMN \\
\hline
\end{tabular}

AS, Aortic stenosis; Al, aortic insufficiency; $C M N$, cystic medial necrosis; STJ, sinotubular junction.

autograft root aneurysm. ${ }^{3-8}$ Therapeutic indications with regard to timing and technique of reintervention have thus far been elusive. ${ }^{1,2}$ Several factors account for the absence of standardized criteria for reoperation, including the undefined natural history of autograft root dilatation, the possible coexistence of a competent neoaortic valve, the scarcity of valid surgical alternatives, and the complexity of redo aortic root procedures with the attendant morbidity. ${ }^{9}$ In general, elective intervention on the neoaortic root has been advised in the presence of moderate or severe neoaortic valve insufficiency or when the aortic root diameter exceeded 55 mm. ${ }^{1,3-8}$ Some authors have also deferred reintervention on the basis of the severity of concomitant pulmonary homograft dysfunction, with the intent to minimize the number of reoperations. ${ }^{4}$ The technique most commonly adopted to replace the dilated aortic root has been the modified Bentall operation using composite mechanical or biologic grafts, with valve-sparing root replacement limited to anecdotal reports. ${ }^{4-8}$ By using this approach, morbidity associated with reoperation has been low. However, the proportion of patients benefiting from neoaortic valve preservation has also proved low, as low as one third of those requiring reintervention. ${ }^{4}$ Our initial approach to the problem of root aneurysm after the Ross procedure has been cautious, thereby delaying reoperation until the appearance of moderate valve insufficiency and progressive left ventricular enlargement. This has resulted in only 1 of 3 patients, the present one, having successful root remodeling with valve preservation (Table 1 ). The case here reported provides evidence that progressive neoaortic root dilatation after the Ross procedure might be complicated by aortic root dissection. From a clinical and histologic standpoint, the presentation is identical to that of native aortic dissection. However, involvement is limited to the aortic root by the distal anastomotic suture line. Whereas brachiocephalic and thoracoabdominal aortic collaterals will be protected by the disease process, any proximal aortic complication is possible, including aortic valve regurgitation, coronary occlusion, or aortic rupture. Although clinically relevant valve insufficiency appeared subtly in the case herein, the untoward events reported above can all occur acutely. Given the impossibility to quantify the risk of neoaortic root rupture and the young age of the patient, indication for reintervention was thus planned on an urgent basis, even in the absence of marked clinical symptomatology. Contrary to the attitude thus far adopted, early treatment of neoaortic root dilatation deserves consideration regardless of valve function because life-threatening complications, such as neoaortic root dissection, are a definite risk.

Similar to previous reports, ${ }^{4,7}$ histologic examination of the excised pulmonary artery wall has demonstrated cystic medial necrosis, with fragmentation and loss of elastic fibers and deposition of mucopolysaccharides. Some authors have proposed that such changes might be related to congenital alteration of the pulmonary artery trunk in patients with bicuspid aortic valve disease. ${ }^{10}$ However, identical lesions have been observed in the pulmonary artery wall of patients with tricuspid aortic valves undergoing post-Ross aortic aneurysm resection at our institution (Table 1), as well as at others. ${ }^{7}$ These findings agree with prior echocardiographic results showing no correlation between neoaortic root dilation and bicuspid aortic valve disease. ${ }^{2}$ Further studies are warranted to define whether autograft root pathology is linked to congenital rather than acquired factors (eg, exposure to systemic pressure or interruption of vasa vasorum).

On the basis of the present report, life-threatening complications of neoaortic root aneurysm, such as dissection or even rupture, are distinct possibilities. Elective resection of the autograft root aneurysm should not be delayed until evidence of valve involvement shows but rather scheduled prophylactically in relation to morphometric parameters, as suggested for the native aortic aneurysm in patients with Marfan syndrome or bicuspid aortic valve disease. ${ }^{11}$ Earlier indication for reoperation might reduce the risk of spontaneous neoaortic root complications and increase the likelihood of autograft valve preservation.

\section{References}

1. David TE, Omran A, Ivanov J, et al. Dilation of the pulmonary autograft after the Ross procedure. J Thorac Cardiovasc Surg. 2000; 119:210-20. 
2. Luciani GB, Casali G, Favaro A, et al. Fate of the aortic root late after Ross operation. Circulation. 2003;108(suppl 1):II61-7.

3. Hokken RB, Takkenberg JJ, van Herwerden LA, Roelandt JR, Bogers AJ. Excessive pulmonary autograft dilatation causes important aortic regurgitation. Heart. 2003;89(8):933-4.

4. Sundt TM, Moon MR, Xu H. Reoperation for dilatation of the pulmonary autograft after the Ross procedure. J Thorac Cardiovasc Surg. 2001;122(6):1249-52.

5. Leyh RG, Kofidis T, Fischer S, Kallenbach K, Harringer W, Haverich A. Aortic root reimplantation for successful repair of an insufficient pulmonary autograft valve after the Ross procedure. $J$ Thorac Cardiovasc Surg. 2002;124(5):1048-9.

6. Schmidtke C, Stierle U, Sievers HH. Valve-sparing aortic root remodeling for pulmonary autograft aneurysm. J Heart Valve Dis. 2002; 11(4):504-5

7. Ishizaka T, Devaney EJ, Ramsburgh SR, Suzuki T, Ohye RG, Bove EL. Valve sparing aortic root replacement for dilatation of the pulmo- nary autograft and aortic regurgitation after the Ross procedure. Ann Thorac Surg. 2003;75(5):1518-22.

8. Masetti P, Davila-Roman VA, Kouchoukos NT. Valve-sparing procedure for dilatation of the autologous pulmonary artery and ascending aorta after the Ross operation. Ann Thorac Surg. 2003; 76(3):915-6.

9. Luciani GB, Casali G, Faggian G, Mazzucco A. Predicting outcome after reoperative procedures on the aortic root and ascending aorta. Eur J Cardiothorac Surg. 2000;17(5):602-7.

10. De Sa MPL, Moshkovitz Y, Butany J, David TE. Histologic abnormalities of the ascending aorta and pulmonary trunk in patients with bicuspid aortic valve disease: clinical relevance to the Ross procedure. J Thorac Cardiovasc Surg. 1999;118:588-94.

11. Svensson LG, Kim K, Lytle BW, Cosgrove DM. Relationship of aortic cross-sectional area to height ratio and the risk of aortic dissection in patients with bicuspid aortic valves. J Thorac Cardiovasc Surg. 2003; 126:892-3.

\title{
Metastatic left atrial synovial sarcoma mimicking a myxoma
}

\author{
Sanjay Kumar, MCh, FRCS, ${ }^{\text {a }}$ Mubarak A. Chaudhry, FRCS, $^{\text {a }}$ Irfan Khan, MRCS, ${ }^{\text {a }}$ David J. R. Duthie, MD, FRCA, ${ }^{\text {b }}$ \\ Steve Lindsay, MD, MRCP, ${ }^{c}$ and Pankaj Kaul, MCh, FRCS (CTh), ${ }^{a}$ Leeds and Bradford, United Kingdom
}

 eart neoplasms are of increasing interest to clinicians and surgeons. A synovial sarcoma of the heart, either primary or secondary in origin, is extremely uncommon. ${ }^{1}$ To our knowledge, this report is the first documented metastatic synovial sarcoma of the left atrium and emphasizes that this tumor, although rare, should be considered in the differential diagnosis of left atrial myxoma. The pathology, clinical implication, and management options are discussed.

\section{Clinical Summary}

A 27-year-old man presented with a 4-month history of palpitations and dyspnea. Of note, there was no history of syncope, constitutional symptoms, or previous asbestos exposure. Within the last few weeks, he had also noticed a tender swelling in his right calf. Apart from the presence of the calf swelling, his physical examination was unremarkable. Transthoracic echocardiography showed a $4 \times 2.5-\mathrm{cm}$ mass arising from the mitral valve and

\footnotetext{
From the Departments of Cardiothoracic Surgery ${ }^{\mathrm{a}}$ and Anaesthesia, ${ }^{\mathrm{b}}$ Yorkshire Heart Centre, Leeds General Infirmary, Leeds, United Kingdom, and the Department of Cardiology, ${ }^{\mathrm{c}}$ Bradford Royal Infirmary, Bradford, United Kingdom

Received for publication March 8, 2004; accepted for publication March 22, 2004.

Address for reprints: Pankaj Kaul, MCh, FRCS, Floor D, Jubilee Building, Yorkshire Heart Centre, Leeds General Infirmary, Great George St, Leeds, West Yorkshire LS1 3EX, United Kingdom (E-mail: pankajkaul@ supanet.com)

J Thorac Cardiovasc Surg 2004;128:756-8

$0022-5223 / \$ 30.00$

Copyright $\odot 2004$ by The American Association for Thoracic Surgery

doi:10.1016/j.jtcvs.2004.03.037
}

adjoining atrial wall (Figure 1). The appearance was deemed consistent with that of a myxoma, although its site of origin was unusual.

The patient was admitted expeditiously for excision of the left atrial mass. Through a median sternotomy, cardiopulmonary bypass was established after aortobicaval cannulation. The heart was arrested with antegrade cold blood cardioplegia. An atriotomy was made in a large left atrium behind the interatrial groove. A large 3 $\times 3.5-\mathrm{cm}$, dumbbell-shaped mass was present in the left atrium. It had a wide origin, arising from the posterior mitral leaflet, posteromedial commissure, adjoining anterior mitral leaflet, and left atrial wall posteriorly. The mass (Figure 2) could not be excised without sacrificing the mitral valve, which was replaced with a $29-\mathrm{mm}$ St Jude mechanical prosthesis. There was a possibility of incomplete resection because the tumor was invading the atrioventricular groove. The patient had an uneventful postoperative recovery.

The histopathologic examination revealed a tumor of mixed cellularity set within focally calcified fibrous stroma-positive margin. Morphologic and immunocytochemical features of the tumor were consistent with the diagnosis of synovial sarcoma. A cytogenetic examination of the excised lesion demonstrated an abnormal triploid clone containing 2 copies of translocation $t(X ; 18)$, which is consistent with the above diagnosis.

After histologic diagnosis of the cardiac tumor, the patient underwent a contrast spiral computed tomographic scan of the thorax, abdomen, and pelvis. No further intrathoracic or intraabdominal lesion was seen. An ultrasound scan of the right calf swelling suggested a discrete lesion with its own intrinsic blood flow, which is consistent with it being a sarcoma. A tru-cut biopsy confirmed this to be a synovial sarcoma. Which lesion, either left atrial or right calf, was the primary and which was the secondary was impossible to determine both histologically and clinically. The 

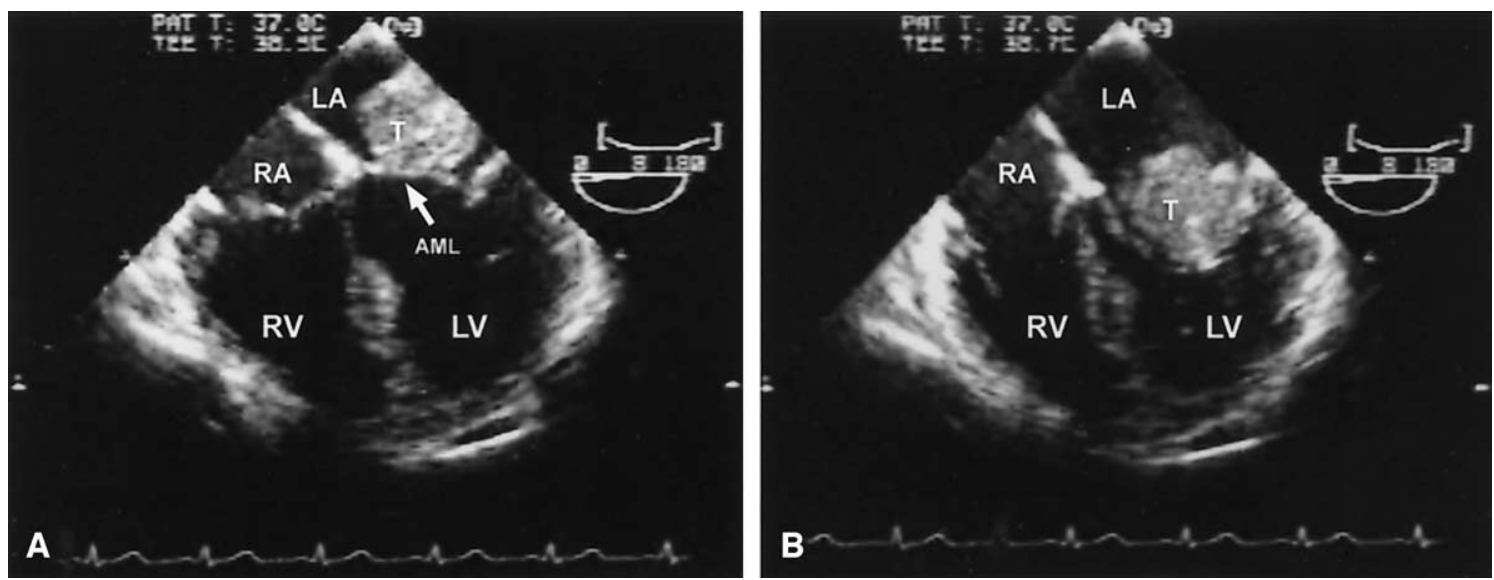

Figure 1. Transesophageal echocardiogram showing the tumor $(T)$ in the left atrium (LA): $A$, attached to the anterior mitral leaflet $(A M L)$ in systole; $B$, protruding through the mitral valve orifice close to the anterior mitral leaflet in diastole. The left ventricle (LV), right atrium (RA), and right ventricle (RV) are also shown.

possibility that both were secondary lesions with an unrecognized primary source cannot be discounted.

The patient received ifosfamide-based chemotherapy. This comprised $9 \mathrm{~g} / \mathrm{m}^{2}$ ifosfamide every 3 weeks for 2 cycles. A spiral computed tomographic scan was performed after completing 2 cycles. Two new areas of abnormalities were seen: a 2-mm nodule in the right lower lobe of the lung and a cluster of small lymph nodes adjacent to the left kidney. A new subcutaneous soft tissue swelling was also present in the right loin posteriorly. The patient was offered second-line chemotherapy with doxorubicin with or without trial agents, but he elected to explore alternative therapies.

\section{Discussion}

Tumors of the heart are rare and are usually benign, with the majority being myxomas. Only $25 \%$ of primary cardiac tumors are malignant, and nearly all are sarcomas. The most common are angiosarcomas (31\%), followed by rhabdomyosarcomas (21\%), malignant mesotheliomas (15\%), and fibrosarcomas (11\%), with synovial sarcomas being extremely rare. ${ }^{1,2}$ However, the most common cardiac malignancy is a metastatic cardiac tumor, being 20 to 40 times more common than primary cardiac malignancies. ${ }^{1}$

The synovial sarcoma itself is an uncommon mesenchymal malignant tumor with epithelial qualities. ${ }^{1}$ The most common primary site for a synovial sarcoma is the lower limb, usually in the para-articular regions. An occurrence outside the synovial-lined spaces is rare, and only a limited number of cases have been documented. They are also known to arise within the abdominal wall, neck, head, mediastinum, lung, or pleura. On rare occasions, these are known to arise within the heart.

There are 7 published reports of primary cardiac synovial sarcomas in patients ranging from 13 to 53 years of age (mean, 40.8 years). ${ }^{1,3}$ Most of these patients presented with syncope or dyspnea. There is an association with previous exposure to asbestos. ${ }^{4}$ These patients might be asymptomatic or might present with transient ischemic attack, pulmonary hypertension, heart failure, or cardiac tamponade, symptoms dependent on location within the heart and associated pathology. ${ }^{5-8}$ Sarcomas present in the left

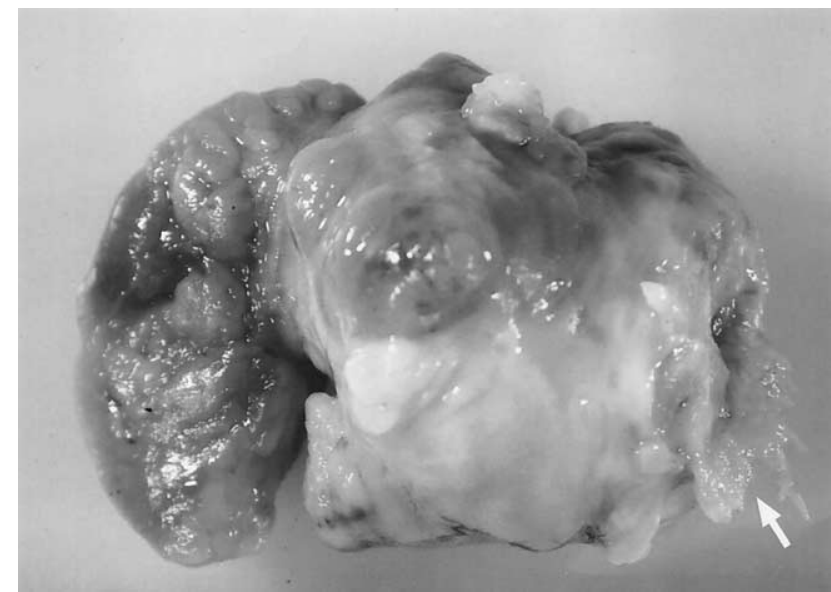

Figure 2. The excised tumor is shown, and the arrow points to the end of the tumor attached to the left atrial wall, the leaflets, and the posteromedial commissure of the mitral valve.

atrium can be easily mistaken for left atrial myxomas because echocardiographically they are indistinguishable. ${ }^{4,5}$ To date, no report of a metastatic arial synovial sarcoma has been published. Because primary synovial sarcomas commonly arise at extracardiac sites, it is likely that in this case the calf lesion is the primary lesion, with metastatic spread to the heart.

The diagnosis of a synovial carcinoma is confirmed by means of identification of a chromosomal translocation, $\mathrm{t}(\mathrm{X} ; 18)$, which is found in more than $90 \%$ of all synovial sarcomas. The distinction between a synovial sarcoma and a primary cardiac mesothelioma of the heart is difficult, and therefore it is important to confirm the $t(X ; 18)$ translocation to verify the diagnosis. ${ }^{1,3,4}$

For primary intracardiac sarcomas with no evidence of metastatic spread, surgical intervention is the mainstay of treatment not only to alleviate symptoms but also to avoid potential complications. As in this case, excision of a valve might be necessary to 
attempt complete clearance. However, complete macroscopic resection is possible in only $33 \%$ of patients. ${ }^{9}$ Invasion of the atrioventricular groove by tumor in this case made complete resection impossible. Recurrence is common even in patients with apparent complete excision. ${ }^{9}$ After surgical intervention, adjuvant radiotherapy for local recurrence and chemotherapy for control of systemic disease might be considered. Heart-lung transplantation has been reported as an option for cure in patients with primary cardiac synovial sarcomas with no evidence of metastatic spread. ${ }^{10}$ This was not an option in our patient because of the likely metastatic involvement of the heart.

Synovial sarcoma of the heart is a disease of young people and carries a poor prognosis. In most reported cases, patients succumb within 1 year of diagnosis. ${ }^{1}$ The most common cause of death is local recurrence $(50 \%)$, even after complete macroscopic resection. ${ }^{9}$ The aggressive nature of the disease might require modification of accepted treatment modalities and sequence.

In retrospect, the unusual echocardiographic features (ie, attachment to the mitral leaflet) in our patient should have raised suspicion. A cardiac magnetic resonance image might have provided more detailed anatomic information and suggested histology. ${ }^{11}$ It can be argued that the usual paradigm of treating potential myxomas urgently should have been disregarded, with the calf lesion investigated first. One cannot help but postulate that cardiopulmonary bypass in this instance might have hastened the dissemination of the tumor.

\section{Conclusion}

Metastatic synovial sarcoma to the left atrium carries a grave prognosis. It should be considered in the differential diagnosis of left atrial myxomas, especially if the echocardiography suggests unusual features.
We thank Mr S. Powell and Ms Ezenee Kolbaba, Department of Medical Illustration, LGI, Leeds Teaching Hospitals, Leeds, United Kingdom, for their help with the illustration.

\section{References}

1. Nicholson AG, Rigby M, Lincoln C, Meller S, Fisher C. Synovial sarcoma of the heart. Histopathology. 1997;30(4):349-52.

2. McAllister HA, Fenoglio JJ Jr. Tumors of the cardiovascular system. In: Atlas of tumor pathology, series 2. Washington, DC: Armed Forces Institute of Pathology; 1978. p. 78.1-78.8.

3. McGilbray TT, Schulz TK. Clinical picture: primary cardiac synovial sarcoma. Lancet Oncol. 2003;4(5):283.

4. Karn CM, Socinski MA, Fletcher JA. Cardiac synovial sarcoma with translocation (X;18) associated with asbestos exposure. Cancer. 1994; 73(1):74-8.

5. Casselman FP, Gillinov AM, Kasirajan V, Ratliff NB, Cosgrove DM. Primary synovial sarcoma of the left heart. Ann Thorac Surg. 1999; 68(6):2329-31.

6. Bittira B, Tsang J, Huynh T. Primary right atrial synovial sarcoma manifesting as transient ischemic attacks. Ann Thorac Surg. 2000; 69(6):1949-51.

7. Constantinou LL, Charitos CE, Lariou CM. Primary synovial cardiac sarcoma: a rare cause of tamponade. Eur Heart J. 1996;17(11): 1766-8.

8. Tak T, Goel S, Chandrasoma P, Colletti P, Rahimtoola SH. Synovial sarcoma of the right ventricle. Am Heart J. 1991;121(3):933-6.

9. Donsbeck AV, Ranchere D, Coindre JM. Primary cardiac sarcomas: an immunohistochemical and grading study with long-term follow-up of 24 cases. Histopathology. 1999;34(4):295-304.

10. Siebenmann R, Jenni R, Makek M, Oelz O, Turina M. Primary synovial sarcoma of the heart treated by heart transplantation. J Thorac Cardiovasc Surg. 1990;99(3):567-8.

11. Hoffmann U, Globits S, Schima W. Usefulness of magnetic resonance imaging of cardiac and paracardiac masses. Am J Cardiol. 2003;92(7): $890-5$. 